Diánoia, vol. 16, no. 16, 1970

\title{
TIEMPO Y ETERNIDAD EN LA METAFISICA OCCIDENTAL
}

El tema "tiempo y eternidad en la metafísica occidental" no solamente lo concibo yo como la tarea de dar un panorama histórico, sino que debe ser más bien ya de por sí una cuestión sistemática relevante, a saber, la cuestión planteada a nuestra gran tradición metafísica occidental, sobre si ésta propuso de una manera adecuada la pregunta acerca del tiempo y de la eternidad, y si la respondió en una forma comprensible para nosotros; para nosotros, que nos experimentamos como seres enteramente histórico-temporales, y sin embargo como interpelados, reclamados en todo momento por lo eterno. Historia no es, por cierto, simplemente devenir, alteración en el tiempo, sino siempre una unidad de sentido, una continuidad significativa del devenir temporalmente humano. Este sentido histórico del tiempo ¿es él mismo a su vez temporal o eterno, relativo o incondicionado, que se transforma $o$ inalterable? El tiempo como tiempo ¿no destruye necesariamente toda supratemporalidad, absolutez o eternidad de una pretensión y exigencia de sentido? El tiempo como tiempo ¿no exige necesariamente el ajuste a la cada vez nueva disposición creada por él, a la cada vez nueva situación histórica? ¿Cómo se enfrentan, por tanto, tiempo y eternidad con respecto a nosotros y a nuestra historia? Por una parte: ¿Es la eternidad solamente una imagen transformable de una nostalgia histórica, una utopía temporal, una escatología ella misma histórica, que en el torrente del tiempo postula su término y meta, por decirlo así, el desembocar de la corriente temporal en la intemporalidad? O por el contrario, ¿no son tiempo e historia otra cosa que la siempre nueva producción de la imagen de la eternidad inalterable y suspendida sobre aquél, imagen que nosotros, sin embargo, no podemos mantener en la historia y ante la cual fracasamos siempre de nuevo una y otra vez en el intento de su realización? ¿Cómo están, pues, relacionados tiempo y eternidad? ¿Es la eternidad la medida del tiempo histórico, cuya conformidad con el notiempo de lo siempre-válido es a la vez su juicio, un juicio que nos condena, porque nosotros en cierta forma jamás satisfacemos a lo eterno en el obrar y devenir temporales? De esta breve reflexión previa resultan dos cosas para las disquisiciones siguientes: I) Éstas pretenden desarrollar la relación de tiempo y eternidad en primera línea con vista a su significatividad para el hombre y su historia, es decir, yo considero el tema desde la antropologia y la filosofía de la historia, y dejo a un lado el aspecto de filosofía natural del planteamiento de la cuestión. 2) Esa pregunta antropológica y de filosofía de la historia sobre el tiempo y la eternidad la formulo yo como pregunta sistemática a nosotros mismos, en tanto nos hallamos en un determinado 
punto temporal de nuestra tradición de pensamiento metafísico, y hemos de establecer posición en ese punto.

Si debemos tomar posición respecto de lo que la metafísica occidental ha dicho sobre tiempo y eternidad, en primer lugar tenemos que preguntarnos brevemente: ¿Qué es esto - la metafísica occidental? Dejemos a un lado por ahora la disputa acerca de la historia del término. Es bien sabido que meta puede traducirse de dos maneras. Meta como "más allá de", trans en latín; o como "después", en latín post. Metafísica como "transfísica", es el ir más allá de la física, de la naturaleza, el trascender la naturaleza en su totalidad: es por tanto un concepto de metafísica relativo al contenido. "Postfísica", en cambio, significa que aquellos escritos que nosotros llamamos metafísica, estaban en la obra de Aristóteles, en el Corpus Aristotelicum, ordenados después de los escritos que ahí se llamaron: tà qvotxó; era una designación bibliotecaria, formal por tanto. La metafísica, cuyo fundador es Platón, llenó tempranamente su concepto relativo al contenido, sin conocer el término metafísica. Ella "trasciende", por tanto, desde su fundación en el Occidente; trasciende, es decir, sobrepasa a la naturaleza. Pero, ¿como qué es tomada aquí "naturaleza", si la metafísica debe sobrepasarla? Naturaleza en este sentido no es, como en los Presocráticos, el todo, el uno omnicomprensivo del mundo unificado, sino que naturaleza es una parte de lo que llamamos mundo, a saber, el conjunto de lo dado inmediatamente a nosotros, de lo que se-muestra-apareciendo-sensiblemente, de lo experimentable temporalmente. En la metafísica - desde su fundación por Platón- se halla una división del mundo en mundo experimentable sensiblemente, el xóouos

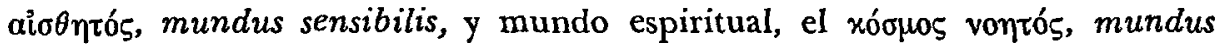
intelligibilis; la división, por tanto, en mundo de la razón, el mundo permanente, por un lado, y mundo de los sentidos, el mundo del devenir, por el otro. El mundo temporal como mundo de los sentidos y del devenir, remite a la razón y a la eternidad de ésta, a un mundo de permanencia, racional e inalterable.

Por metafísica en este sentido tradicional se puede, pues, entender el cumplimiento de esta indicación: explicar todo ser desde ese dualismo del mundo doble, desde la escisión del mundo uno en ambos mundos. Estos dos mundos, el mundo metafísico y el físico, se diferencian para el metafísico griego, así como se diferencian para él, de un lado, el ser como permanencia, como razón, como supra-tiempo, como eternidad, como absolutez, como incondicionado, y de otro, el devenir como lo sensible, lo temporal, lo condicionado, lo relativo, lo cambiante y lo inestable. La no-estabilidad es señal de nuestra sensibilidad, la que en cada momento se invierte y tiene otros 
dolores, otros gozos, otras afecciones, otras sensaciones, otras impresiones; esa inestabilidad es al mismo tiempo nihilidad, pues únicamente el ser "es", como lo estableció Parménides; el no-ser, en cambio, niega el presente permanente. El "ser" eterno se enfrenta al "no-ser" temporal. Nuestro mundo humano, compuesto de los dos mundos del devenir temporal y del ser eterno, es designado, por ende, en la terminología platónica como un $\mu \iota x \tau o ́ v$, algo mezclado, como una mezcla, $\mu \tilde{i} \xi \iota 5$, en la que el ser, como eternidad, se fragmenta luego temporalmente, al enajenarse la unidad racional, inmediatamente permanente, en la multiplicidad, en el ingreso a la pluralidad de lo temporal-sensible. Exactamente en este sentido definió más tarde Hegel, el gran consumador de la metafísica griego-occidental, el tiempo como el serfuera-de-sí del espíritu. El espíritu mismo penetró en su nihilidad que lo fragmenta y con ello se hizo a la vez temporal. A partir de aquí la historia es en primera línea acontecimiento de una disminución del ser, de una fragmentación de la unidad, y su meta ha de ser su propia superación: la supresión del tiempo, la supresión de la historia en el retormar-nuevamentea-sí, cerrado cíclicamente, del espíritu, el cual se reconquista de nuevo después de su enajenación. Este restablecimiento aparece metafísicamente como el sentido de la historia, que, atravesando por el tiempo, debe superar a éste, y es consumación de la negatio negationis; aniquilar el tiempo quiere decir negar la nada, extinguirla nuevamente.

Esta posición metafísica de un craso enfrentamiento entre tiempo y eternidad, entre ser y devenir, entre estabilidad y mutación, tuvo, como es sabido, su punto de partida en la Antigüedad, con Sócrates, en la problemática ética. Lo que permanece, es el debe eterno, que como arquetipo, como

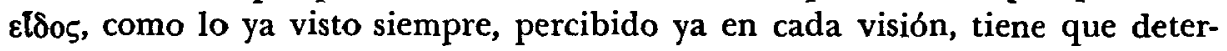

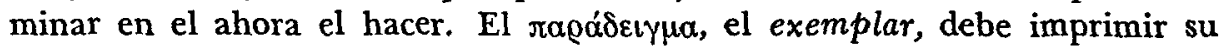
sello a lo momentáneo; y con ello el devenir, que incomprensiblemente se nos escapa de las manos, es acuñado por lo permanente, por la razón, por el arquetipo, y la fugaz actividad recibe un "carácter" como obrar moral, y con ello un permanecer relativo, un ser relativo. Esta metafísica dice: el devenir en sí es inconcebible; y habría dicho esto ya a través de Parménides

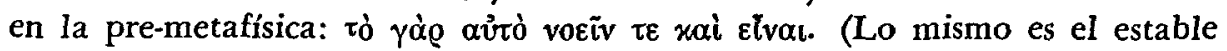
percibir espiritual y el haber percibido y su percepto, el ser.) Sólo la razón percibe lo estable, uno, siempre-igual, unido consigo mismo, lo mismo. Los sentidos, en cambio, tropiezan con la multiplicidad desconcertante, insostenible, infijable, cambiante; unidad, eternidad, racionalidad y multiplicidad, temporalidad, sensibilidad, se contradicen y con todo se remiten las unas a las otras.

¿Se da una mediación y un medio de esta dualidad y oposicionalidad, o solamente oposición y mezcla? Pero de esto depende que nosotros podamos comprender positiva o negativamente lo humano, lo "de aquí". Si sólo 
se da una mezcla, que es un enturbiamiento, una enajenación, un ex-propiamiento, entonces somos propiamente sólo hombres, para dejar de nuevo tras nosotros el ser hombre. Entonces ser hombre es solamente la forma de aparición temporal, es decir, inestable, del espiritu estable, debido, permanente, invariable; entonces no somos propiamente "hombre", sino "espíritu" y debemos llegar a serlo de nuevo en el tránsito a través de nuestro ser-hombre temporal. Que nosotros nos defendamos contra ello a cada momento, y que toda la época moderna se haya opuesto a ese ex-propiamiento metafísico de lo humano o de lo "de aqui" -como lo expresa Rilke-, esto es conocido para todos. Historia no sería en este enfoque nada positivo: historia de una realización debida; sino que sería sólo algo negativo: existiría para llevarse a sí misma a la desaparición. Ahora bien, en la metafísica ¿se permanece siempre en este dualismo, o encuentra ella alguna vez el auténtico medio, la auténtica mediación, sin renunciar a él por ello en cuanto metafísica, esto es, sin negar la diferencia entre eternidad y tiempo? ¿Cómo es en ella esa posición entre eternidad y tiempo? ¿Es el tiempo sólo el enajenamiento, la aniquilación de la eternidad, o se da también para él aquel medio, semejante al cual nosotros los hombres actuales consideramos de buen grado a la historia, a saber, aquello donde lo eterno, en el centro del tiempo y no "sobre él" mismo, adquiere en cuanto tal quizá primero la realidad que le es propia? Contemplemos, pues, la historia de la metafísica precisamente con el fin de saber si existe para ella sólo el enfrentamiento, la separación, la mezcla enajenadora de ambos, o si no se muestra también aquí, à pesar de todo, una unidad originaria de esa separación de tiempo y eternidad; y si con ello, a pesar de todo, no oculta en sí tal vez -desarrollado o no desarrollado- el arranque de un ingreso hacia la historia entendida modernamente. Así pues, ¿̇se ofrece a la visión de la historia de la metafísica occidental en algún sitio una unidad originaria de tiempo y eternidad? Ésta es nuestra pregunta.

II

Empecemos muy brevemente de nuevo en Platón, el "fundador": Lo eterno se llama aquí lo aǐbov. Es lo ở ờv, lo que es perpetuamente permanente, y lo permanente es lo övtws öv, lo único que es propiamente, que excluye de sí el devenir, que no está "en" el tiempo, sino "sobre" el tiempo. Este supratiempo sería entonces la eternidad platónica, la validez perpetua, intemporal, que se mantiene a través de todo el tiempo, que se muestra como "intemporal", porque el tiempo no es capaz de hacerle nada, aun cuando entre ella en el tiempo. Pues el tiempo es tiempo, porque tiene tres dimensiones. Lo intemporalmente válido, en cambio, no se preocupa ni por lo "sido", ni por lo que va a ser, o por lo que solamente ahora es, sino que llana y simplemente es. La duración, la persistencia en el tiempo es sólo la 
representación de la validez intemporal de la eternidad; la duración es la imagen de la eternidad. Únicamente la perpetuidad, la inalterabilidad, puede ser el símbolo de la eternidad. El ser como persistencia y duración presenta a la eternidad en un "esquema", temporal, en una imagen temporal, representa en el tiempo a la eternidad. Así surge una posición fundamental enteramente "conservadora". Lo divino, lo eterno, se hace visible en lo que se mantiene inalterable. Lo que se mantiene en forma inalterable posibilita el conocimiento, pues éste es interpretado de manera platónica como la relación de lo múltiple que deviene con lo uno permanente, ya siempre conocido. El acto moral aparece en este horizonte como la impresión configuradora del paradigma inalterable sobre el hacer cambiante actual. El siempre haber visto ya del espíritu posibilita la comprensión del devenir sensible en la unidad de una significación válida y la unificación de la actividad múltiplemente atareada en orden a la forma ética válida. Así pues, lo importante es que lo múltiple participe de lo uno, lo que deviene de lo permanente; está en juego la relativa estabilización del devenir, que jamás puede tener éxito completo, sin aniquilar el devenir, está en juego la relativa eternización de lo temporal. Pero, ¿no importa también la relativa fluidificación de la persistencia temporal, la temporalización misma de lo eterno? Esta pregunta no se plantea así dentro de la metafísica platónica.

Conviene, por tanto, preguntar por el acontecimiento, en donde ambas cosas pueden realizarse, en donde el devenir recibe una relativa persistencia en la "participación" y donde lo eterno se abaja a permitir la "participación". Todo, por tanto, se dirige al punto donde se realiza la conversión de eternidad en tiempo. Conversión se dice en griego $\mu \varepsilon \tau \alpha \beta a \lambda \eta \dot{~ . ~ S e ~ c o n v i e r t e ~}$ la unidad, en cuanto que pasa a multiplicidad y hace que la multiplicidad participe en ella. Se convierte la eternidad en tiempo, el ser en devenir, la validez en facticidad, la norma en lo normado. ¿Dónde se realiza esta conversión? Con esta pregunta se hallan Platón y la metafísica ahí "donde nosotros los queremos tener". Este problema es tratado especulativamente en los grandiosos análisis del diálogo tardio Parménides. Según éste la conversión no sucede "en" el tiempo; pues precisamente debe convertirse la eternidad en tiempo, el ser en devenir. Esta conversión en tiempo es un devenir distinto del devenir en el tiempo. El lugar donde tiene efecto la conversión,

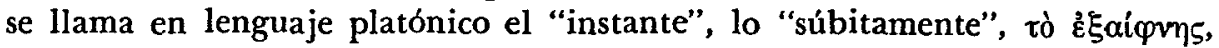
en latín subito. Un hermoso tratado de Werner Beierwaltes estudia la historia del pensamiento del $\mathfrak{\varepsilon} \xi$ aípuns desde Platón, pasando por Aristóteles, el Pseudodionisio Areopagita, Meister Eckhart, hasta Kierkegaard, quien lo ha elevado a punto central de su filosofía de la religión y de su teología. ${ }^{1}$ Beier-

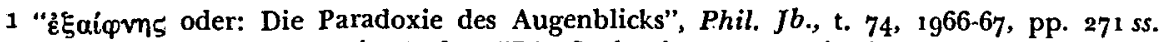
Cfr. también al respecto: Martin Puder, "Die Synkopierung von Ėรaipvns und võv", Phil. Jb., t. $76,1968 \cdot 69$, pp. 420 ss. 
waltes señala los dos pasajes decisivos donde se explica este enigmático "súbitamente", en el cual eternidad se convierte en tiempo, validez en facticidad, ser en devenir, unidad en multiplicidad; en su necesariedad es explicado especulativamente, como se acaba de decir, en el diálogo tardío Parménides, el más difícil de todos los diálogos platónicos; como experiencia. en cambio, como acontecimiento, como sufrimiento del hombre, en cierto

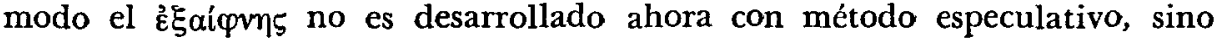
descrito, precisamente descrito en forma poética, en aquella famosa Carta VII de Platón, la que los filólogos han rechazado muchas veces como inauténtica, para retornar siempre de nuevo a su persuasiva autenticidad.

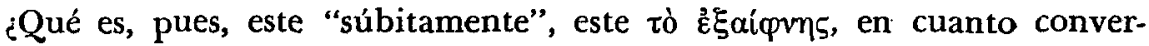
sión de eternidad en tiempo, y de unidad en multiplicidad, y según ello en cuanto comienzo de todo movimiento temporal en el Parménides? Es la participación como proceso, no como estado, la $\mu \varepsilon \dot{\varepsilon} \theta \varepsilon \xi\llcorner$, la participatio de lo temporal en lo eterno, de la múltiple representación en el uno por representar, de las operaciones normadas en la norma una; aquí en el Parménides, conforme se acaba de decir, aparece ella no como algo estático -según lo describe casi siempre la historia de la filosofia- sino como un pro-ceso, como un acontecimiento, como el tránsito del reposo del ser al movimiento del ente como algo que deviene (ôv $\gamma(\gamma v o ́ \mu \varepsilon v o v)$. El tránsito al tiempo no puede - según el pensamiento de Platón- tener efecto en el tiempo, pues entonces estaría ya sin duda comprendido por el tiempo. Él es la entrada en el tiempo, y con ello el instante mismo, como encuentro de eternidad y tiempo, no está en el tiempo. El instante es intemporal. Es la negación de todo tiempo determinado. Es el proceso que mueve en medio del tiempo, y sin este proceso del consentimiento de la partícipación el tiempo no podría ser tiempo. El instante no está sometido al tiempo; pero está en medio del tiempo, temporizado, posibilitando, haciendo surgir al tiempo. Se lo llama tò

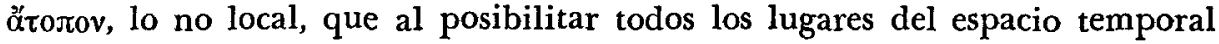
primero los hace ser. Es el problema del empezar absoluto, del comenzar simplemente que se le plantea a todo tiempo, el que es discutido aquí. Más de 2000 años después Kant recogió de nuevo este problema, lo reflexionó y repensó muy detalladamente. Dentro de la Crítica de la razón pura-que propiamente habría de llamarse "Crítica de la razón pura teórica"-, dice él que este problema sobre el comienzo del tiempo, o de sí mismo "antes" de sí, no puede resolverse téricamente, porque por igual se puede decir: no puede haber ningún comienzo del tiempo, como: tiene que haber un comienzo del tiempo. Pero prácticamente se da, con todo, aquel experimentado fenómeno que llamamos libertad. La libertad es comprendida en Kant bajo el concepto superior de causalidad. Existe una causalidad de la naturaleza, la cual significa que en la continuidad temporal cada "antes" está enlazado con un "después" mediante la ley, de que una sucesión legal corresponde a 
una sucesión temporal. Todo lo que es causa de un efecto, es al mismo tiempo ya efecto de una causa precedente. Libertad, por el contrario, es únicamente causa, pero no efecto también. Si la libertad fuera también efecto, no sería libertad, porque entonces estaría ya determinada por algo diverso de ella misma. La libertad como espontaneidad, la libertas spontaneitatis, está caracterizada por el hecho de que no es ninguna "consecuencia de...", pero supone, tiene consecuencias. Ella no puede ordenarse dentro de un antes y un después, pero sí tiene un después que atrae hacia si, como efecto de su novedad. La libertad no puede encontrarse en el tiempo; solamente lo que se sigue de ella, está bajo la "ley del tiempo". En cuanto que la ciencia como tal vincula en el tiempo sus experiencias con la posibilidad de una eventual pronosticabilidad, el fenómeno de la libertad, según Kant, no pertenece a la ciencia, pero sí pertenece a la vida humana. Pues no hay nada más cierto que la libertad, que este primer inicio mismo como realidad de la autodeterminación. La realidad de la autodeterminación y de la determinación libre entra en el tiempo, no está en él, y por ello la libertad es también para Kant la irrupción de lo nouménico en el mundo fenoménico. el cada vez nuevo ingreso de lo indeterminable en el mundo determinado y en el mundo de las determinaciones explicables. La libertad no "está" en la contextura de una experiencia. Experimentar y experiencia son propiamente para Kant sólo la contextura legal de los fenómenos, que son explicados en su contextura mediante la ley que debe encontrarse. Más bien la libertad es experimentable sólo como discontinuidad de la continuidad, como irrupción de lo cada vez nuevo en lo que jamás es enteramente nuevo, la naturaleza. Pero ya era también así en Platón. Pues en éste lo eterno es, no como se lo expone en la mayoría de los casos, solamente lo que ha sido ya siempre, lo que en la ảváuvmoı,, el recuerdo, es sólo nuevamente "destacado", reconstruido. El lugar de lo eterno no es únicamente el recuerdo. El

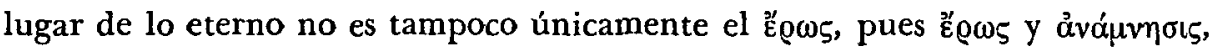
recuerdo y amor, son sin duda lo mismo, en tanto que se ama lo que nosotros hemos sido ya siempre, hemos sabido y solamente hemos perdido en la frag. mentación temporal; y el inicio que queremos repetir es al mismo tiempo la meta del amor, hacia la cual nos dirigimos. No únicamente ảvó $u v \eta \sigma \iota s$ y ع̋@os son el lugar donde surge lo eterno, sino que esto tiene al instante como lu-

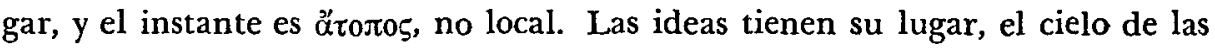

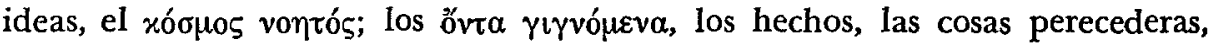
tienen su lugar, $\dot{\eta} \gamma \tilde{\eta}$, la tierra. Cielo y tierra son lugares. Lo eterno no tiene como lugar ni el cielo ni la tierra. Lo eterno es lo ảyatóv, y tiene el tójos újou@ávios aún más arriba del cielo. No es ninguna forma fija, permanente,

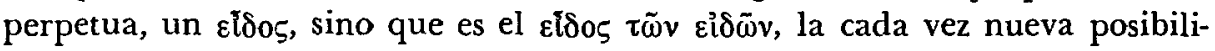
tación absoluta de las ideas, las cuales han sido posibilitadas por la irrupción; esta irrupción sucede a la manera del rayo, según se dice en la Car- 


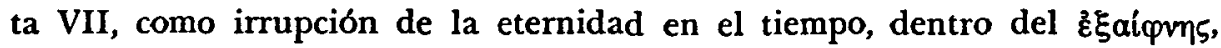
de lo enigmático del "súbitamente". En él no irrumpe una idea que nos diga qué ha de hacerse, un arquetipo que deba ser copiado en lo que deviene, sino lo absolutamente irrepresentable, tò ảya oóv, el bien, que domina sobre todas las normas, sin poder él mismo ser captado como una norma permanentemente estable. Lo eterno como $\dot{\alpha} \gamma \alpha \theta \delta$, es el fundamento de la per-

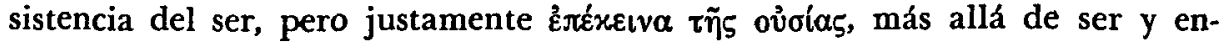
tidad, la nada positiva, el misterio real. Lo último, por tanto, no es lo visible y perceptible, sino lo que la visión hace surgir mediante su relampaguear y brillar. No es una aparición, sino un brillar, que hace surgir a la razón misma, la razón sin sujeto y sin objeto, nuestra razón perceptiva y lo que ella piensa; en cuanto "origen" existe antes del mundus intelligibilis y del mundus sensibilis y sin embargo no es simplemente un más allá que sea construido, sino su verdadera articulación experimentable en medio del tiempo, en cuanto que ese brillar está ahí en el $\tilde{\varepsilon} \xi \alpha i \varphi v \eta \xi$, en el acontecimiento de lo súbito, en donde el "ah"" pre y suprarracional de lo eterno hace posible que la razón sea razón, y hace posible que la sensibilidad vea sensiblemente. Así, lo persistente, lo permanente, la duratio, la duración ya no son la imagen de lo eterno, sino el "instante". Aquí se asoma la gran posibilidad de una historia "kairótica" o "kairológica", una historia que no es predecible como la reproducción del debe eterno, al que el devenir por cierto jamás satisface. Si en el platonismo se hubiera seguido este punto de arranque del $\grave{\varepsilon} \xi \alpha i ́ \varphi v \eta 5$, quizá esta filosofía se habría transformado en una filosofía de lo cada vez nuevo imprevisible, que siempre se halla a la base de una previsión, es decir: de una "filosofía del espíritu" habría llegado a ser quizá una "filosofía de la libertad incalculable". Pero tal vez se habría transformado también sólo en una "mística de la libertad" y como tal en su subjetividad y deficiente validez universal, quizá se habría rezagado detrás de cada forma de metafísica. Esta pregunta debe quedar aquí sin discutirse, a saber, sobre si la no consideración del significado central de este ớtoxov, de esta falta de lugar del instante, dio poder a la filosofía para ser metafísica y para evitar la mística, o si esta no consideración ha sujetado a la filosofía en los límites de una "metafísica del espiritu" y descuidado con ello la auténtica oportunidad histórica de una reflexión sobre la libertad.

\section{III}

Mas pasemos ahora de esta primera aparición y reflexión de nuestro problema a ulteriores y decisivos puntos de referencia de la reflexión sobre eternidad y tiempo en la metafísica occidental. La famosa definición de Aristó-

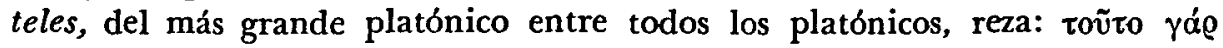

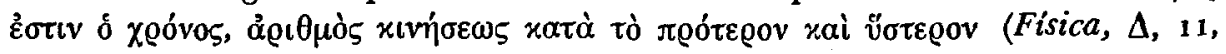


219 bss.). En latín pasó a todos los libros de texto de la Edad Media y aun llegó a los comentarios de Tomás de Aquino en esta forma: tempus est numerus motus secundum prius et posterius: "Tiempo es el número del movimiento en su calidad de numerado según antes y después." Pues bien, tiempo como número del movimiento según antes y después plantea sin embargo la siguiente problemática lógica: antes y después son precisamente determinaciones temporales. Pero, quien intenta definir un fenómeno como concepto con los propios elementos de éste, según la lógica antigua y medieval, no puede definir, pues ejecuta algo lógicamente prohibido. Ahora bien, Aristóteles definió el tiempo con algo temporal, ya que determina el número del movimiento según su anterioridad y posterioridad, según su antes y después. Pero antes y después son en su unidad tiempo. Por tanto, define el tiempo mediante algo temporal. ¿Es, por tanto, un movimiento circular, que está vedado por la lógica? De ninguna manera; pues por "anterioridad" y "posterioridad" no se entiende aquí, como se ha comprobado siempre, lo anterior y posterior temporales, sino el orden de la fundamentación. El fundamento es "antes" de lo fundado, y por ello se da un orden en el fundamentar aun ahí donde no se significa en absoluto ninguna sucesión temporal, por ejemplo en la matemática intemporal y en sus argumentaciones demostrativas. Si el orden de la fundamentación entra en el tiempo, en lugar de la inclusión y yuxtaposición, en lugar de la reunión de fundamento y fundamentado, se da una separación en el espacio y el tiempo. Entra una distentio, una distensión, que sin embargo tiene su "fundamento" en la diferencia entre fundamento y fundamentado; y la separación de fundamento y fundamentado en el espacio y el tiempo constituye luego al fundamento

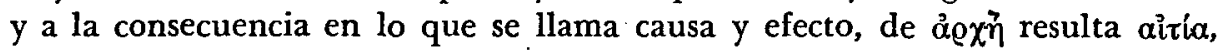
de ratio resulta causa. El espacio, por ejemplo, no es en Aristóteles algo originario, sino el espacio intermedio, el espacio ocupado, que las cosas producen al colocarse; es un accidente, algo consecutivo; y asimismo, el tiempo es siempre el tiempo ocupado, empleado, requerido, consumido. El "orden-fundamento" inespacial e intemporal es anterior a todo estar ordenado espacial y temporal, y sólo entra en aquél como su fundamento. Para Aristóteles el movimiento no tiene su apriori en el tiempo, sino que en el movimiento se origina el tiempo como consumado. Este movimiento se crea su tiempo, al trasladarse el verdadero orden de fundamento y consecuencia, como un orden de la razón, como un orden del ser, a la nada del afuera de espacio y tiempo, al revóv,

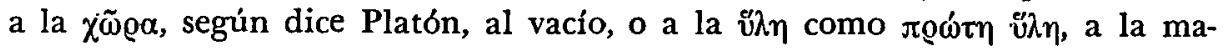
teria como prima materia, como nada informe - según la llama Aristóteles. Sólo entonces se da una verdadera temporización, que en ese sentido significa un casamiento del ser con la nada, del espíritu con lo no espiritual. Pero entonces, ¿cómo se puede contar absolutamente? El tiempo no puede contarse a sí mismo y sin embargo es el número de esa desprendida sucesión 
de lo interiormente homogéneo. El espíritu es el que cuenta; y mientras cuenta el espíritu, el tiempo forma parte de él como derivado del espíritu. El espiritu mismo percibe todavía su impotencia en el fuera-de-sí. En el tiempo el espíritu cuenta la sucesión de su aniquilamiento en el vacío. Tiempo es la dominación de la nihilidad por medio de la razón que reflexiona y cuenta. La nada se coordina con la sensibilidad, la sensibilidad con la enajenación, la enajenación con el devenir, con la no-persistencia. En ese sentido el tiempo es captado de nuevo puramente en la negación del espíritu a partir de éste. La diferencia respecto de Platón no necesita ser considerada más largamente: el $\dot{\varepsilon} \xi \alpha i \varphi v \eta s$ desaparece, y en su lugar se presenta el $v \tilde{v} v$, el ahora, esa "articulación" entre tiempo y eternidad. Este võv es incaptable, porque es un punto interseccional que no tiene extensión alguna; pero ese punto interseccional no es ya ningún acontecimiento, como en Platón, sino abstracción y construcción; y con ello el grandioso análisis temporal del Parménides platónico y de la Carta VII va a perderse en Aristóteles como punto de arranque positivo. El resultado es éste: hay tiempo sólo cuando el serfuera-de-sí, el no-ser, el ser en el vacío, el no ser en sí, nuevamente contado, es recogido por el espíritu que reflexiona al volver atrás. Hay tiempo, por tanto, sólo porque hay $\psi u x \eta ́$, porque hay alma y en el alma voũs, espíritu: tempus non est sine anima, tiempo y temporalidad no son algo simplemente por sí, sino que son en virtud del alma que cuenta, la cual sólo puede contar, porque, existiendo antes del tiempo, constituye a la vez a éste y lo domina. Así llegamos en nuestra visión de conjunto a San Agustín, para quien precisamente esta referencia es la decisiva.

\section{IV}

El famoso análisis agustiniano del tiempo, que ha sido elogiado a través de los milenios, ocupa el libro XI de sus Confessiones. Esa maravilla del tiempo, que sin duda "es", que sin duda "se da", pero que sin embargo, si deseo expresar lo que es, de pronto ya no es y se sustrae al entendimiento que trata de captarla, aun cuando desde siempre la haya utilizado y entendido: esta maravilla del tiempo es abordada de nuevo una y otra vez en todo este libro XI. Si yo quiero captar el "tiempo" mismo y no sólo algo temporal, entonces lo veo primero separado en sus dimensiones, de las cuales en cierta forma está compuesto. Si me acerco a esas dimensiones, encuentro que ninguna de ellas, a pesar de todo, merece el predicado "es". Porque, tiempo es, por ejemplo, el pasado; y pasado es ya-no-ser, por tanto, no-ser; o bien: tiempo es el futuro, que aún no es, por tanto, aún-no-ser; o bien: el tiempo es considerado como el ser-ahora, sin embargo, el ser-ahora no tiene ninguna extensión, pues es el tránsito; aquel tránsito, donde el futuro se precipita en el pasado, el aún-no-ser en el abismo del ya-no ser: la convergencia de dos 
"no". El tiempo se temporiza según San Agustín desde el futuro, que se convierte continuamente en pasado; cada vez se hace mayor el ya-no-ser en cuanto ser pasado y en cierta forma cada vez se hace menor el espacio libre del futuro, mientras que el ahora no puede captarse en absoluto, porque significa un simple punto de aniquilación del futuro en el seno del pasado. "Ser", empero, quiere decir perdurar, tener persistencia, stabilitas, immutabilitas, duratio. El tiempo está, por tanto, contra el ser. Del tiempo vale decir que no sólo hay devenir en él. Él no es solamente el espacio de ese devenir nulo (y el devenir destruye por cierto la persistencia, destruye el ser); no, él mismo es un devenir, él mismo "deviene", se temporiza desde el futuro, pasando por el presente, que sin extensión ni sostén es incaptable, y entrando en el ya-no-ser del haber sido. Y sin embargo, el tiempo es. ¿Cómo es el tiempo? El futuro todavía no es y sin embargo "es" en su aún-no-ser, en cuanto que yo lo espero; la fuerza de la exspectatio hace un praesens de futuro, da a lo futuro no presente su futuridad misma entitativa, tan peculiarmente esperada. La memoria, el recuerdo, hace del pasado ausente, del praeteritum, la presencia de lo que está lejos, el praesens de praeterito. Y entonces se da un praesens de praesenti, un presente de lo presente; pero éste, ¿acaso no se muda y es insostenible? $Y$ sin embargo, es sostenido en la "atención", en la attentio, en la advertencia que lo sostiene, mientras realmente es tarea el mantenerlo. Conciencia es una corriente, un rio - Edmund Husserl nunca se cansó de repetir esto siempre de nuevo. Pero ese fluir desde el futuro, como exspectatio y praesens de futuro, hacia el pasado, que existe en la memoria como praesens de praeterito, pasando por sobre aquello que en la attentio recibe impresa la persistencia como praesens de praesenti, es recogido de nuevo. Exspectatio es protentio, prolongarse; memoria es retentio, retroextenderse; attentio es extenderse hacia y asirse; protentio, attentio y retentio tienen su unidad en la intentio, en la verdadera distensión del hombre, en la extensión y dilatación, que es su verdadero ser. Pero, ¿qué es esta intentio, esta distensión, y cómo es posible? Solamente es posible por medio de la mens, el espiritu, y en la mens se da la acies mentis, el filo, la agudeza del espíritu, y en este punto de la agudeza del espíritu ocurre la illuminatio, la irrupción de lo eterno en aquel tiempo, que es nuestro tiempo. Nuevamente describe San Agustín esto como un acontecimiento, una experiencia, que le ha sucedido a él y que ha de suceder en cada hombre, si es que el hombre debe ser hombre. La experiencia se lleva a cabo por ejemplo en el acontecimiento de la verdad; respecto de la verdad yo no pregunto por cuánto tiempo es verdadera la verdad, cuándo fue verdadera, cómo será verdadera; por decirlo así, es indiferente con relación al tiempo. En el tiempo se experimenta - si es que la verdad es experimentada-, cómo algo supratemporal entra en el tiempo y da a éste fundamento, medida y sostén. Así mismo es experimentada luego también la bienaventuranza; ninguno de no- 
sotros fue alguna vez bienaventurado y tampoco lo será mientras exista como hombre; y sin embargo, todos nosotros sabemos acerca de la bienaventuranza, pues siempre medimos nuestra dicha con relación a ella, siempre podemos preguntar: ¿es esto lo que nosotros propiamente queremos? ¿Corresponde esto a lo que propiamente nos ha sido destinado? Lo absoluto se experimenta aquí en cuanto medida. ¿Cómo se experimenta en cuanto medida? Como un ofrecimiento absoluto. El futuro absoluto, que no es ya un futuro calculable, golpea como un rayo y llega al tiempo. Mas para que nosotros tengamos futuro, espera, no solamente como algo que está fuera, a lo cual nos dirigimos, sino como algo que tenemos delante de nosotros en cuanto futuro, para ello se necesita que midamos ese estar fuera, lo objetivemos, lo representemos bajo la unidad de algo que absolutamente está fuera y sea incondicionado; ahora bien, esa unidad de lo incondicionado del futuro es la bienaventuranza. $\mathrm{Y}$ así mismo medimos nosotros cada experiencia, al compararla como experiencia con otra, según la medida de lo que ha de valer siempre y ha valido, según el pasado absoluto, la verdad. El ahora lo medimos nosotros no según una medida cualquiera fuera de él, sino conforme a lo que es experimentado como plenificación del presente en general, partiendo en lo posible del futuro y pasado absolutos. En este sentido podemos exponer nuestro presente, el futuro y el pasado en cuanto tales, bajo una medida que ha de ser, sin embargo, algo experimentado; esta experiencia es la irrupción de la illuminatio, en la cual lo eterno, como medida absoluta, irrumpe dentro de mi vida. Así mi presente es medido luego conforme a lo que puede en general ser presente, mi futuro de acuerdo con el futuro simplemente absoluto, y mi estrecho pasado conforme al pasado absoluto; y esto lo puedo yo sólo porque hago la experiencia de la illuminatio, de la irrupción, que ocurre en la acies mentis, y por cierto fuera de lugar y tiempo, äนoлov, en el $\vec{\xi} \xi \alpha i \varphi v \eta 5$ como irrupción de una vida absoluta en esta vida limitada. Eternidad es vida absoluta, que se manifiesta en la vida sin límites - no es, por tanto, duración ni extensión-, sino que la suma intensidad de la vida es la imagen realmente experimentada de esa vida eterna. En lugar del símbolo extensivamente temporal (la duración), entra el intensivamente cualitativo (la iluminación).

\section{V}

Esta sustitución de la duración cuantitativa por la intensidad cualitativa como símbolo real de la eternidad ocurre también en aquella famosa y muy citada definición postagustiniana de Boecio, que luego Tomás de Aquino adoptó nuevamente. ¿Qué es en ella la eternidad? Pues bien, no se la toma como duración ilimitada, ni como stabilitas, ni como immutabilitas, como inalterabilidad absoluta, sino como un acto, y por cierto, un acto absoluto: "aeternitas est tota simul et perfecta interminabilis vitae possessio". Tota possessio 
-la posesión completa, perfecta - consumada sin velos, de un acto vital, interminabilis: al que no se han puesto límites, y que se lleva a cabo simul -en un instante, que no conoce dimensiones, ni extensión alguna, ni precesión o sucesión. Eternidad es definida así como instante de vida, que sin disociación posee el todo en el "instante", en el "ahora". Mas esa eternidad le corresponde sólo a Dios como Dios, y ni Santo Tomás ni Boecio describen esa experiencia del simul en nosotros. Ella le es dada a Dios en cuanto Dios y le permanece negada al hombre en cuanto hombre.

En Tomás de Aquino hay dos conceptos de lo aeternum. Uno es el aeternum secundum se, lo eterno en sí; para éste vale aquella definición que se remonta hasta Boecio y que no puede aplicarse asi al hombre. El otro concepto es el aeternum participative, aquel aeternum que sólo es enunciable mediante una relación de participación en lo propiamente eterno; es la eternidad en imagen, en representación en el tiempo, el concepto análogo de la eternidad. En su lugar está luego la immutatio, la interminabilidad, la in-. variabilitas, lo diuturnum, lo que dura por encima del tiempo, que se mantiene en el tiempo como imagen de la eternidad. Decisivo para toda la época siguiente es que este aeternum per se queda reservado puramente a Dios en cuanto Dios y que el aeternum secundum quid en cuanto representación o reproducción, adecuada y análoga, admite la immutabilitas, la stabilitas y lo diuturnum como características en general y absolutamente como válidas. El ser es ser eterno, el ente es algo alterablemente temporal. La eternidad no está concebida aquí como el núcleo del tiempo, sino como lo opuesto al tiempo. El tiempo es la enajenación de la eternidad, y sin embargo, aun en esta enajenación, él puede señalar análogamente hacia la eternidad como a su oposición, representarla en la relativa duración e inalterabilidad.

Esto tiene una multitud de consecuencias en todas las formas de pensamiento, a las que se designa luego, siguiendo a Santo Tomás y a sus contemporáneos filosóficos, como escolástica, escolástica tardía, escolástica moderna, neoescolástica y así sucesivamente. Un ejemplo al respecto podría ser el "derecho positivo" temporal-histórico, el cual, sin duda, en una proporción tremenda es las más de las veces "derecho": pues un derecho que careciera de la positividad, sería ciertamente menos que si tiene la positividad. Ahora bien, en todas las direcciones escolásticas el derecho positivo viene a ser "derecho menor", frente a aquél "derecho natural" intemporal, que, por sobre toda la historia, a saber, en todas las épocas, en todos los lugares, en todos los desarrollos y generaciones, habría de cumplirse en la misma forma, acomodándose no obstante cada vez, si es necesario, a determinadas circunstancias de modo accidental. Un auténtico derecho-histórico no es ya posible según esta concepción de la eternidad, que ya no está en el tiempo, sino que queda reservada a Dios fuera del tiempo. El "verdadero" derecho, entonces, como toda verdad, tiene su lugar por encima de la historia: en el Dios 
suprahistórico y en su "imagen" entre nosotros: el espíritu suprahistórico. Así mismo, la ética viene a ser imposición de lo eterno, de lo intemporal, en el tiempo; pero esto quiere decir que ahora y siempre está contra el tiempo. Y así, desde esta metafísica de la oposición, en la que el tiempo puede contener tan sólo una imagen insuficiente de lo eterno -pero no este

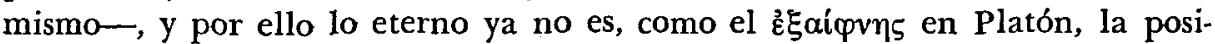
bilitación interna del tiempo mismo en el tiempo, en esta metafísica, pues, ya no puede desarrollarse ninguna comprensión auténtica de la historia y con ello tampoco ninguna verdadera autocomprensión del hombre histórico. Este tiempo "metafísico" mismo no puede en verdad jamás ser normativo como el físico, sino sólo fáctico; él es el auténtico "en-donde" de la caída de lo eterno y del vano intento de hacer inválida la caida. La historia entera del hombre sería entonces, por decirlo así, sólo el vano intento de hacer inválida la historia, el cual sin embargo jamás tiene éxito. En esta perspectiva lo eterno es únicamente conocible en la verdad inalterable, y la verdad inalterable es la verdad de la razón, del espíritu. Mas el espíritu es el inalterable ser-en-sí intemporal y ahistórico, que es inalterable, porque no es perturbado por ningún afuera, y no se tiene que confrontar con nada. De allá procede luego la disposición de que Dios, el en verdad eterno, sea captado puramente como espíritu; y la libertad, vista desde aquí, es siempre sólo un accidente del espíritu. Libertad quiere decir hacerse libre de la alteración, de la sensibilidad, del tiempo; es aquella autarquía, aquella autosuficiencia, que sólo se alcanza, cuando yo esté sustraído al tiempo o me sustraiga al tiempo, cuando supere al mundo, "me vuelva todo espíritu", o bien - como Dios- sea yo mismo. Las consecuencias de esto para toda la actitud vital y la ascética pueden verse fácilmente desde ahí.

\section{VI}

¿Cuál es, pues, la situación actual de la cuestión antropológica y filosóficohistórica de la problemática de "tiempo y eternidad"? Yo quisiera poder conectarme una vez más con el punto de arranque del problema en Immanuel Kant: para él, como ya se mencionó, el tiempo es la forma a priori de la intuición sensible. Sólo en la sensibilidad, por tanto, se da el tiemppo; de un lado está la razón y con ella la intemporalidad, del otro lado la sensibilidad y con ella la temporalidad. Y entonces surge el gran problema del "esquematismo" en Kant, el problema del medio. ¿Se da un verdadero medio entre razón y sensibilidad, entre intemporalidad, eternidad y carácter temporal de devenir? Si la sensibilidad es la virtud de ser afectable que se transforma cada vez de nuevo, la facultad de ser tocable múltiplemente infinita, seguro que no tiene en sí a la vez el poder de darse previamente, en orden a la multiplicidad, la unidad del tiempo mismo. La virtud del dar 
previamente la unidad para la sensibilidad, empero, no puede tampoco producirla la razón - como lo total y absolutamente ajeno a la sensibilidad-; sino que aquí tiene efecto luego el famoso recurso de Kant en la primera edición de la Crítica de la razón pura a la "imaginación productiva". La fantasía es ciertamente sensible, pero a la vez también productiva, espontánea-activa. Tiene rasgos determinantes comunes a la razón y a la sensibilidad. En su importante libro sobre Kant, Heidegger interpreta en este sentido la fantasía como el oculto medio entre razón y sensibilidad, como lo propiamente decisivo, como lo verdadero humanum hominis. Pero, ¿qué es la fantasía? Fantasia no es por cierto el imaginarse alguna cosa fantástica cualquiera; sino que fantasía, facultad imaginativa, es verdadera fantasía ahi donde creadoramente libre nos presenta un vínculo que ata en verdad ahora. En lo más profundo, fantasía es la liberación del mero impulso sin la urgencia de la racionalidad que siempre prescribe. La esencia de la fantasía es la libertad, y la esencia de la libertad es la fantasía. Fantasía es, entonces, la facultad real que proyecta las determinadas posibilidades, capaces de enlazar (que son al mismo tiempo las posibilidades por realizar). Sin embargo, toda esta interpretación de Kant ha sido sumamente discutida. En Kant, por cierto, no es el tiempo creador e histórico el tiempo temporizado por la imaginación productiva; sino que el tiempo no deja de ser un esquema formal, que permanece siempre igual a sí, y es siempre el mismo tiempo neutral, mientras que el dar previo, que verdaderamente enlaza, ha de ser un dar previo del tiempo histórico. Sin embargo, aquí está abordada con razón la fantasía en cuanto tal, aun cuando no sea concebida en su plena forma concreta. $\mathrm{Ni}$ en la razón ni en la sensibilidad entra lo eterno en la historia, en los hombres, sino únicamente en la fantasía se manifiesta en verdad Dios, el que absolutamente dispone en el campo de la libertad; y el mostrar-se de Dios sucede, por ende, más que en la ciencia y en la filosofía, ahí donde la fantasía está instalada en su derecho más propio: en el arte. El homo artifex es el más humano y con ello el más divino hombre que en general se pueda representar, y no el homo philosophicus, ni tampoco su contrario: el homo faber. Fantasía es libertad. Tiene que darse una forma de libertad, que sea al mismo tiempo teórica y práctica, que proyecte libremente y que, sin embargo, nos obligue a nosotros mismos, que nos diga qué ha de hacerse. El hombre sin fantasía jamás puede decir lo que ha de hacerse, si no le ha sido dado previamente el código de las normas siempre iguales, es decir, la supuesta revelación del mundus intelligibilis. Ciertamente es del todo válido que quien no ha experimentado la irrupción supratemporal de lo nouménico en cuanto libertad —como lo expone Kant-, tampoco sabrá jamás que, absolutamente, la libertad es la que ata el tiempo. La fantasía, que puede proyectar un mundo venidero, futuro, como la forma exigida de nuestro ser mundano y humano, sólo tiene, sin embargo, la verdadera fuerza vinculadora, en tanto 
reduce a representación no solamente el "que" del vínculo, sino también su "qué" y "cómo" (y esto lo hace, por ejemplo, en el arte y en la política). Mientras los moralistas carezcan de fantasía, la moral no podrá tener verdadera fuerza creadora y obligatoria momentánea, "instantánea". En Kant, sin embargo, después de haber visto primero el carácter nouménico de la libertad y la posición central de la fantasía, ocurre de nuevo la gran recaída en la antigua metafísica de la oposición. Pues, een qué reconozco yo, según él, el acontecimiento de la irrupción de la libertad como una libertad imperativa, es decir, su norma obligatoria? Kant dice: en su universalidad, en su repetibilidad, en su igualdad en todos. Con ello se restablece nuevamente la antigua oposición entre unidad y multiplicidad, entre sensibilidad y suprasensibilidad, entre persistencia formal del ser y cambio transformador del contenido; y el medio creador de la imaginación productiva ("creativa"), ha sido entregado a la fantasía normativa. No es necesario exponer aquí cómo en Hegel se intenta dinamizar la estática. Algo eterno, separado y "para si", no puede darse según él, pues lo que es por sí y separado, no es absoluto, no es incondicionado, tiene un límite, un enfrente, algo otro, un fuera-de-sí. Lo eterno "es" en cuanto se representa en el tiempo e integra a éste nuevamente como un todo y lo recoge en sí, "superándolo". Mas esto quiere decir que el verdadero suceso en el tiempo es el despliegue del espiritu en la nihilidad. Tiempo significa para Hegel enajenación necesaria y la más indispensable exterioridad, a fin de que mediante la exteriorización pueda tener éxito aquel regreso a sí mismo, por el que la historia universal recibe un contenido y para que el espíritu se vuelva espíritu plenificado. El tiempo está ahí para ser superado, a fin de que en su superación lo eterno reciba un contenido, que él por sí no puede tener en absoluto. En esa forma sucede entonces el movimiento cíclico. "El tiempo - así dice Hegel literalmente- aparece por ende como destino y necesariedad del espíritu, que no está perfecto en sí y se resigna a su no perfección, para poder ser perfecto." Lo que es verdadero, es eterno en sí y para sí; pero no fue válido ayer y mañana no será válido; para Hegel vale el "es" absoluto, aquel ahora, que no es el ahora que desaparece sensiblemente, sino la integración del todo en el espíritu mismo. Tampoco aqui es posible una verdadera historia, pues todo está predeterminado en el proceso de la enajenación y la reducción. Así como la concepción de la historia como Ética vio el mundus intelligibilis, el mundo eterno estático, por el cual tenemos que resolvernos, como pura estática; así la concepción de la historia como evolución muestra ciertamente una dinámica, pero en la necesariedad, no en la libertad. Todavía al final tiene que ser alcanzado el comienzo, pero ahora como plenificado. La historia universal puede construirse en esta perspectiva; si yo conozco sus principios, los principios del espíritu, la lógica, puedo determinar previamente su curso. Lo mismo sucede también, en el fondo, en Teilhard de 
Chardin, quien pretende construir el curso de la historia universal claramente en vista del punto omega y ve un progreso siempre mayor; pero él no ve cómo toda ganancia se obtiene con pérdida y cómo cada tiempo tiene verticalmente su inmediatez en relación con el Absoluto. Ser hombre significa ser histórico; y ser histórico es posible solamente en la dinámica libre de la historia, donde lo eterno no está contra el tiempo, donde el tiempo no sólo enajena a lo eterno o tiene que reproducirlo siempre de la misma manera o se mueve hacia él, para terminar ahí, sino donde lo eterno es lo más profundo del tiempo, el å̃oлtos tóros, el lugar no local, desde donde puede absolutamente darse la historia, y desde donde la historia no conoce ya ningún final pleno de sentido y ninguna anulación predeterminada, sino que está "justificada" en sí misma siempre y en todo tiempo. De tres maneras se muestra lo eterno en cada existencia-temporal humana. Nadie ha expuesto esto en forma más grandiosa que Franz Rosenzweig en su original Stern der Erlösung. ${ }^{2}$ Lo eterno, como lo absoluto, se muestra en cuanto posibilidad de lo mismo, del mundo y de Dios. Todos estos tres autotestimonios son, sin embargo, lo "mismo"; en primer lugar lo mismo: ello lo abarca todo. No hay nada que no pueda estar en la conciencia, en el pensamiento, en el Yo. Volviendo atrás de todo, llego nuevamente al Yo; también a Dios lo pienso como $m i$ Dios, el mundo siempre como $m i$ mundo, al otro como alguien que me es adecuado u opuesto. El Yo, lo mismo, es lo eterno absoluto, ilimitado, que vuelve detrás de cada una de sus apariciones. Luego, el mundo. También el yo está en el mundo, también Dios pertenece al mundo; el mundo es la posibilidad que lo abarca todo. Y finalmente Dios. Dios no conoce algo diverso fuera de sí; si conociera algo diverso, no sería Dios; Él no conoce ningún término, ningunos límites, pues lo abarca todo. Él es él futuro absoluto de todo. En todas las tres formas se muestra lo eterno como libertad. Lo mismo se muestra primariamente en la conciencia, en aquel llamado inmediato, para que una y otra vez me remueva a mí mismo libremente, para que me comprenda a mí mismo de nuevo; lo mismo es lo eterno como pasado absoluto. El mundo es lo eterno como presente incondicionado, respecto del cual libremente me he de resolver y decidir, el que he de elaborar y establecer actualmente, si no quiero fracasar. Dios es el futuro absoluto, la libre esperanza de aquel todo que no conoce ya ninguna diferencia ni oposición, y sin embargo no me absorbe, sino que me deja ser, me deja libre como el que soy. La conciencia, que mirando atrás me llama absolutamente a la renovación; la esperanza, que mirando hacia adelante me llama de modo absoluto a la eternidad de la libertad por esperar; y el mundo, que me llama en forma absoluta al Absoluto

2 Véase al respecto la excelente exposición de Bernhard Caspar en Das dialogische Denken. Un estudio sobre la importancia de Franz Rosenzweig, Ferdinand Ebner y Martin Puder para la filosofía de la religión. Friburgo, Basilea, Viena, 1967, pp. 69 ss. 
presente, respecto del cual me tengo que decidir -en todos los tres se manifiesta que cada una de las tres dimensiones temporales es al mismo tiempo una forma real, verdadera y no enajenada, de la eternidad como libertad; que eternidad y tiempo "están", una y otro, dentro, junto y mezcladamente.

Hasta aquí la metafísica ha confrontado siempre lo eterno y lo temporal. Antes existía una jerarquía estática no arbitraria o una evolución dinámica necesaria. Ahora, empero, en este "instante" de nuestra historia ideológica, conviene pasar a la historia libre. Esta "historia libre", sin embargo, sólo es posible si lo eterno ha irrumpido "ahi" en cada una de las dimensiones temporales como dimensiones históricas y si en todo tiempo existen el "instante" y la "continuidad de todos los instantes".

Martin Heidegger distingue: "el ente es", "el ser se da"; "se da ser", "se da tiempo". 3 . Ser como tiempo se me da imperativamente no como lo construible en un catálogo de lo que ha de ser, sino en el ahora, en lo que ha de ser ahora apodíctico. Así se actualiza aquí la posibilidad anteriormente indicada, pero omitida, de alcanzar un concepto cualitativo del tiempo, en vez de uno cuantitativo, donde la medida no es la duración, sino la plenificación, la "coincidencia", la "dicha"; en oposición al symbolon, a lo coincidido, yo he llamado al acontecimiento de la coincidencia el symbolos, cuyo "tiempo" es el kairos. Una nueva metafísica, que remplace a la clásica, tiene que ser metafísica de la libertad histórica, no del espíritu intemporal. La medida no es una eternidad del más allá, sino aquella que irrumpe y ha irrumpido, la cual pueda hacer de cada tiempo un $\pi \lambda \hat{\eta} \varrho \omega \mu \alpha$, una plenificación de los tiempos. La "plenitud del tiempo" puede existir siempre en todas partes, porque siempre se da en el ahora la realidad de la eternidad. La verdadera energía histórica en el hombre como "existencia" -conforme lo ha expuesto singularmente Heidegger en su obra temprana- es la "cura". ¿Qué está en juego en la "cura" del hombre? Su poder-ser. Pero, ¿qué es el poder-ser? No es el despliegue de sus disposiciones, la evolución; o bien sólo la "lucha por la existencia" y el afirmarse e imponerse. Sino que la cura es cura por el "salir bien". La cura por el "salir bien", empero, tampoco es aquella preocupación porque nosotros jamás satisfacemos del todo a las exigencias de la ética en cuanto exigencias intemporalmente eternas, tan estrictas, a causa de la distancia respecto del mundo superior. La "verdadera cura" es que no tenemos abiertos los ojos para la presencia de lo eterno en el tiempo, en el instante y para las instantáneas exigencias de lo eterno en el ahora. La "verdadera cura" es la cura porque pasamos de largo ante la revelación de lo eterno; ocurrida cada vez de nuevo: no en el tiempo, sino en cuanto tiempo. Si el hombre estuviera sujeto sólo a la ética, sería llevado

3 Cfr. la conferencia de Heidegger: "Zeit und Sein", del $3^{1}$ de enero de 1962 , impresa por primera vez en: L'endurance de la pensée, Festschrift für Jean Beaufret, París, Plon, 1968, pp. 16-71 (alemán con traducción francesa), publicada ahora en Zur Sache des Denkens, Tubinga, 1969, pp. 1-25. 
a la desesperación como quien fracasa. Ahora bien, la historia se lleva a cabo en una esperanza cada vez nueva. Sin embargo, la metafísica de la esperanza sólo puede tener su esperanza procediendo de la experiencia del mostrarse aquello, que hace posible una esperanza, la de lo eterno presente. ¿Dónde debería mostrarse lo eterno y estar presente, si no es en el instante?

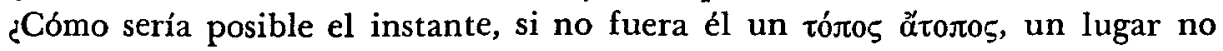
local, es decir la libertad, que sólo experimenta su necesariedad en tanto actúa y se procura su lugar? Por tanto, yo soy de la opinión de que el problema antropológico y filosófico-histórico decisivo sobre cómo se relaciona la eternidad en el tiempo, sólo puede acometerse en una metafísica de la esperanza como metafísica de la libertad. Para una "nueva metafísica" semejante, que supere a la metafísica clásica, sin embargo, tenemos hasta ahora sólo algunos puntos de arranque o indicios. Uno de los más hermosos indicios me parece ser el esbozo (esquisse) -emprendido por cierto con medios del todo insuficientes- del gran pensador francés Gabriel Marcel para una métaphysique de l'espérance. ${ }^{4}$

UNIVERSIDAD DE MUNICH

MaX MüLler

[Trad. de Bernabé Navarro]

4 Homo viator, Philosophie der Hoffnung (traducción alemana de: Homo viator. Prolégomènes à une métaphysique de l'espérance). Düsseldorff, 1949. 